\section{Capturing the Sun, Creating a Clean Energy Future}

The solar energy that reaches the Earth in one hour is about as much as the total energy used by everyone on the planet for an entire year. Capturing just a small portion of that energy could power homes and businesses with a clean, renewable resource that would lead to America's secure energy future. Today, solar technologies provide heat, light, hot water, electricity, and even cooling people around the world. With so many uses and so much potential, solar technologies are a major part of the fast-growing clean technology sector. The sector is experiencing record sales, increased demand, massive manufacturing growth, and significant job growth.

The U.S. Department of Energy's (DOE) broad-reaching strategy has one clear purpose: achieve high market penetration of solar energy technologies by driving down costs. In doing so, the solar industry will create jobs and economic prosperity, while protecting the environment and realizing America's clean energy future. In February 2011, DOE announced the SunShot Initiative which redoubles efforts to reduce the costs of solar energy systems, aiming for $75 \%$ cost reduction so solar is cost-competitive with other forms of energy, without subsidies, before the end of the decade.

\section{About the Solar Program}

Through partnerships with industry, academia, and national laboratories, the DOE Solar Energy Technologies Program sponsors research and development (R\&D) in addition to activities designed to transform the solar market and reduce the cost of solar power. Activities include:

- Solar Photovoltaics (PV) R\&D to significantly improve the cost, reliability, and performance of solar electric devices, components, and systems;

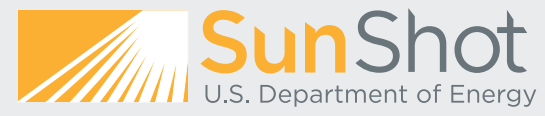

As recently as 1995, the United States held a dominant position in global solar supply and manufactured approximately $43 \%$ of the total PV cells and modules on the market worldwide. By 2010 , America's manufacturing leadership eroded to about a $7 \%$ market share. A core objective of the SunShot Initiative is reversing this trend, stimulating domestic manufacturing, and returning the U.S. to global solar manufacturing leadership.

SunShot accelerates and advances DOE research efforts to make large-scale solar energy systems cost-competitive without subsidies by the end of the decade. Focused on the total installed cost of solar systems, the initiative leverages the strengths of several DOE offices to achieve this ambitious goal.

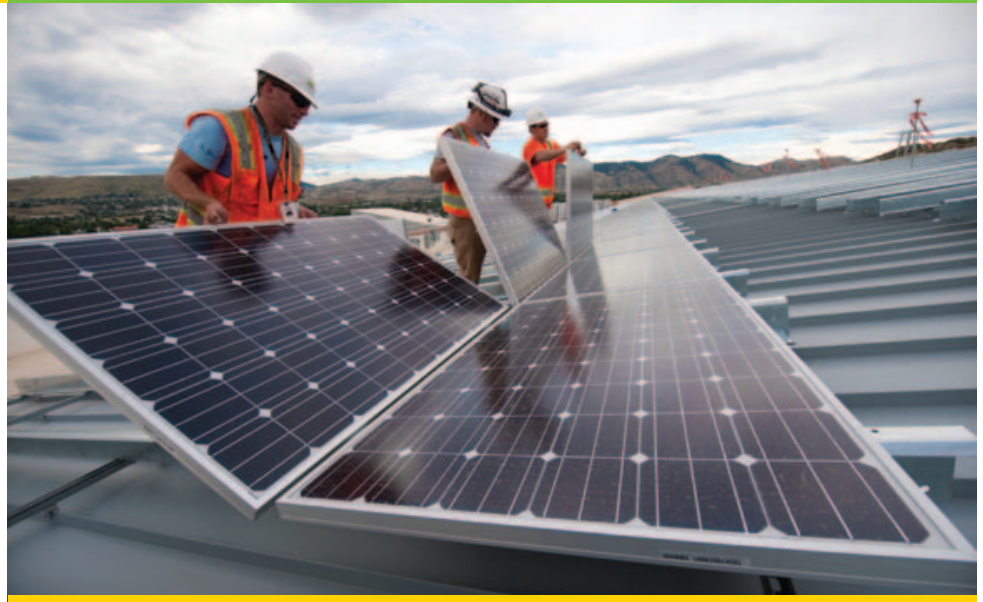

PV panels being installed on the roof of the Research Support Facility (RSF) at the National Renewable Energy Laboratory in Golden, Colorado. Photo by Dennis Schroeder, NREL/PIX 17843

- Concentrating Solar Power (CSP) R\&D to improve utilityscale, solar thermal power systems and demonstrate effective storage technologies;

- Efforts to overcome technical barriers to integrate large-scale deployment of solar systems into the electric grid, reduce the cost of balance of system (BOS) hardware, and reduce the risk associated with commercializing new technologies; and

- Activities to spur solar market transformation, increasing solar power deployment and reducing the nonhardware BOS costs associated with permitting, interconnection, inspection, installation, and other business processes.

\section{Multiple Approaches, One Goal}

In 2010, DOE's Solar Program provided \$247 million to accelerate the research, development, and deployment of solar technologies. Due in large part to efforts funded by DOE, the cost of electricity from PV has dropped more than tenfold since 1976. Improvements in performance and cost will continue to open new markets for solar technologies in the future.

\section{Photovoltaics}

The program provides technical and funding assistance to R\&D projects along the entire PV development pipeline, including new solar electric devices and processes, prototype design and pilot production, and systems development and manufacturing. One such funding opportunity - the SunShot Incubator Program — has provided \$59 million to 24 companies, leveraging $\$ 1.3$ billion in private capital since 2007. Those 24 companies now employ more than 1,200 U.S. workers.

\section{Concentrating Solar Power}

The program encourages solar thermal technologies development with more efficient energy-capturing components 


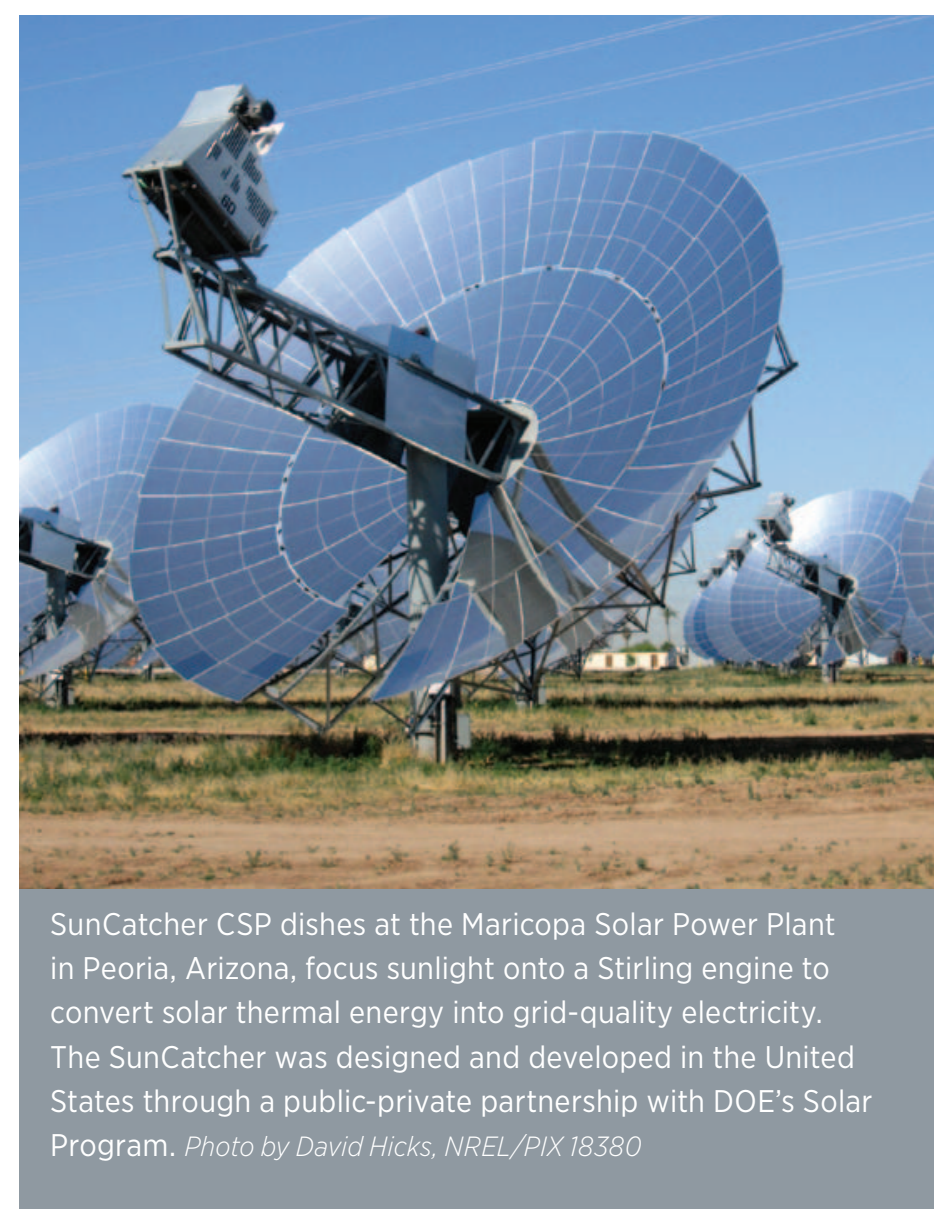

and energy storage capabilities. DOE-sponsored improvements during the past 15 years have reduced the cost of this technology by two thirds. Achieving the SunShot goal, however, will require another two thirds reduction. To increase performance while lowering costs, DOE is exploring high-temperature power conversion systems, polymer reflectors, and low-cost collectors. The higher temperature operating system can increase conversion efficiency from $40 \%$ to $52 \%$ and lower storage costs by nearly $60 \%$. More than 480 megawatts (MW) of CSP are currently in operation in the United States, with another 1,400 MW under construction, and more than 7,600 MW under development.

\section{Systems Integration}

Integrating large amounts of solar generation into the grid leads to many challenges, but the solar program tackles these issues head on. Expert research and analysis on the nation's distribution and transmission grid will help enable solar technologies to provide $14 \%$ of the nation's electricity by 2030 safely, reliably, timely, and cost-effectively. The program also reduces technology risk through testing and evaluation, increasing reliability, and updating codes and

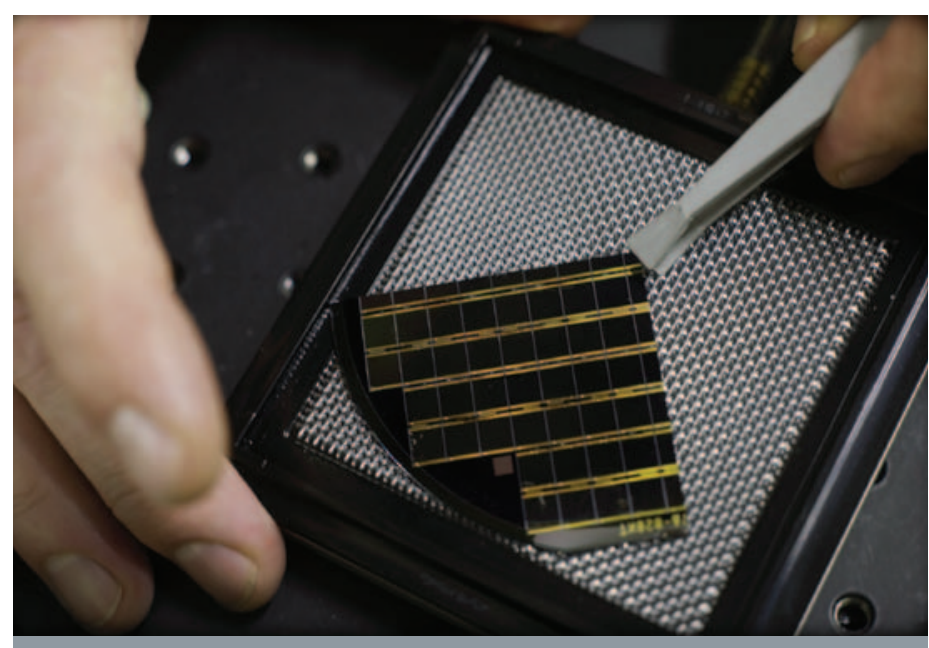

Solar cells developed by Solar Junction through SETP's PV Incubator program undergo testing in a high-intensity solar simulator. Photo by Dennis Schroeder, NREL/PIX 18579

standards. Lastly, for solar to become cost-competitive with other forms of energy, the program is reducing the cost of BOS hardware through funding opportunities and publicprivate partnerships.

\section{Market Transformation}

What is "market transformation?" It means shifting America's energy landscape from fossil fuel dependency to secure, clean energy power, including solar energy. The program is increasing domestic solar market penetration by removing regulatory barriers and reducing nonhardware system costs. Cities and counties across the U.S. maintain disparate permitting and regulatory processes. Through its Rooftop Solar Challenge, DOE focuses on streamlining these permitting procedures to make it easier for families and businesses to install solar energy systems. Another element of transforming the energy landscape includes training. For example, DOE developed a Solar Instructor Training Network that will enable local educational institutions to develop high-quality programs to train system installers and code officials, among others. This effort will result in up to 1,400 trained instructors and 170,000 workforce-ready students over the life of the five-year project.

\section{Learn More

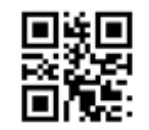

solar.energy.gov

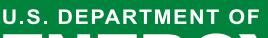 ENAROY}

Energy Efficiency \& Renewable Energy eere.energy.gov solar.energy.gov 